\title{
The effects of ageing on tactile function in humans
}

\author{
Sarah McIntyre ${ }^{1}$, Saad S. Nagi ${ }^{1}$, Francis McGlone ${ }^{2}$, Håkan Olausson ${ }^{1}$ \\ 1. Center for Social and Affective Neuroscience, Linköping University, Sweden \\ 2. Research Centre in Brain \& Behaviour, Liverpool John Moores University, Liverpool, United Kingdom
}

\begin{abstract}
Ageing is accompanied by a steady decline in touch sensitivity and acuity. Conversely, pleasant touch, such as experienced during a caress, is even more pleasant in old age. There are many physiological changes that might explain these perceptual changes, but researchers have not yet identified any specific mechanisms. Here, we review both the perceptual and structural changes to the touch system that are associated with ageing. The structural changes include reduced elasticity of the skin in older people, as well as reduced numbers and altered morphology of skin tactile receptors. Effects of ageing on the peripheral and central nervous systems include demyelination, which affects the timing of neural signals, as well as reduced numbers of peripheral nerve fibres. The ageing brain also undergoes complex changes in blood flow, metabolism, plasticity, neurotransmitter function, and, for touch, the body map in primary somatosensory cortex. Although several studies have attempted to find a direct link between perceptual and structural changes, this has proved surprisingly elusive. We also highlight the need for more evidence regarding age-related changes in peripheral nerve function in the hairy skin, as well as the social and emotional aspects of touch.
\end{abstract}




\section{Highlights}

- With age, touch sensitivity declines, and gentle touch becomes more pleasant.

- Skin elasticity is reduced, and skin tactile receptors are reduced or altered.

- Axonal loss and demyelination affect the amount and timing of neural signals.

- The brain undergoes changes to somatotopic organisation, and many broad changes.

- The link between perceptual and physiological age-related changes remains elusive. 


\section{Introduction}

It is well-known that ageing is associated with reduced sensitivity in hearing, vision, taste, smell, proprioception, vestibular function, and touch. For all these modalities the decline in sensory functions is typically observed above the age of 60 years. However, the sensory decline is not general across sensory modalities and can affect one modality whilst sparing others (Cavazzana et al., 2018). Among the senses, aging of the touch system is one of the least studied, particularly regarding the social and emotional aspects of touch. Tactile impairment may have a profound impact on the quality of life, since touch is crucial not only for handling objects and detection of stimuli, but interpersonal touch is also crucial for strengthening bonds and communicating emotions (Hertenstein et al., 2009; McGlone et al., 2014; McIntyre et al., 2019).

\section{Changing properties of the skin}

Skin aging is characterized by wrinkles and loss of firmness and elasticity (Zhang and Duan, 2018) which may negatively influence the skin-neural coupling. However, the evidence is mixed as to what extent the physical properties of the skin contribute to the decline in touch discrimination (Skedung et al., 2018; Aimonetti et al., 2019). Many elderly people have a good capacity to discriminate between different levels of surface roughness despite the cutaneous condition, and the more important mechanisms for touch impairments with age are likely to be found within the cutaneous nervous system (Skedung et al., 2018).

\section{The peripheral nervous system}

The functionally most crucial factors for the decline of discriminative touch with age are likely to be found within the peripheral nervous system including skin receptors, mechanotransduction processes, and nerve fibres. Tactile afferents innervating the skin are 
pseudounipolar neurons with the cell body in the dorsal root ganglia or trigeminal ganglia. The peripheral part of the tactile afferent projects to the skin and the central part connects to the dorsal horn of the spinal cord (or the brainstem for the trigeminal nerve). The long peripheral axon innervates specialized end organs (Merkel, Ruffini, Meissner, and Pacinian types) or ends in free nerve endings in the dermis and epidermis (Lumpkin and Caterina, 2007), which either surround hair follicles or terminate in the superficial layers of the skin. The specialized receptor endings may serve to mechanically magnify or filter the forces imposed on the skin. Animal studies have shown that the brain-derived neurotrophic factor (BDNF) and tyrosine receptor kinase (TrkB) are important for the development and function of mechanoreceptors (Botchkarev et al., 1999; LeMaster et al., 1999; Cabo et al., 2015).

It has long been known that there is an overall decrease in the number of nerve fibres in the dermis and epidermis with age (Verdu et al., 2000; Besne et al., 2002; Chang et al., 2004). There is also a well-known decrease in nerve conduction velocity and amplitude of the compound action potential of sensory neurons with age (Bouche et al., 1993; Palve and Palve, 2018). A number of histological studies have counted touch-sensitive peripheral neurons in humans and reported age-related reductions in myelinated fibres in the spinal roots (Corbin and Gardner, 1937) as well as evidence of degeneration of both myelinated and unmyelinated fibres in peripheral nerves (Ochoa and Mair, 1969; Tohgi et al., 1977). Recently, a pilot study on human biopsies described prevalence of toxic neuroproteins during aging which may explain some dysfunctions (Akerman et al., 2019). However, more detailed studies on the mechanisms of age-related changes in individual mechanosensitive afferent neurons and their axonal transmission of action potentials are scarce. For example, to our knowledge, there are no single afferent recordings (microneurography) from aged skin in humans.

\section{Mechanotransduction}


The primary mechanotransduction process for many touch-sensitive neurons has recently been discovered in an animal model. Skin deformation is translated into action potentials in the nerve via stretch-sensitive ion channels called Piezo2 (Ranade et al., 2014; Woo et al., 2014; Chesler et al., 2016). Piezo2 channels open in response to mechanical forces applied to the cell, allowing charged ions to enter, triggering action potentials (Wang et al., 2019). In the mouse, Piezo2 expression is found in the nerve endings of several types of touch-sensitive primary afferent neurons, including those that terminate around hair follicles, in Meissner corpuscles in the glabrous skin, and in Merkel cells that are found in both hairy and glabrous skin (Ranade et al., 2014).

Very little is known regarding age-related changes in mechanotransduction. One human study measured multiunit electrical activity in touch-sensitive primary afferent neurons in the median nerve, comparing their responses to mechanical stimulation of the skin and electrical stimulation of the nerve. They reported an age-related decline in the ratio of mechanical to electrical response (Schmidt and Wahren, 1990; Schmidt et al., 1990). This could be due to less reliable transduction in the aging touch system, or due to the loss of receptor endings.

\section{Receptor endings}

In the glabrous skin, thickly myelinated, $A \beta$ touch-sensitive primary afferents are associated with four different receptor endings, as described earlier. Mechanical stimulation of Merkel cells causes a continuous irregular firing of action potentials, and the $A \beta$ nerve fibres that are connected to the Merkel cells are electrophysiologically termed slowly adapting type 1 (SA1) afferents. Expressed in other words, the SA1 afferents connected to the Merkel cells continue to fire as long as the skin is mechanically deformed. The irregular firing pattern of the SA1 receptor is thought to be due to its morphological organization with separate branches of 
the stem axon supplying the individual Merkel discs (Iggo and Muir, 1969; Lumpkin and Caterina, 2007).

Mechanical stimulation of Ruffini corpuscles causes a continuous regular firing of action potentials, and the connected nerve fibres are electrophysiologically termed slowly adapting type 2 (SA2) afferents. The regular firing pattern of the SA2 receptor also seems consistent with the morphology of the Ruffini ending, wherein an undivided axon enters the capsule and bifurcates to form an intracapsular terminal arborization (Chambers et al., 1972). However, the regularity of discharge disappears at low firing frequencies (Wellnitz et al., 2010), which can lend ambiguity to the differentiation between SA1 and SA2 responses.

Mechanical stimulation of Meissner corpuscles causes 'on' and 'off' responses in the connected axon, and the afferents are electrophysiologically classified as rapidly adapting type 1 (RA1). Thus, the RA1 axons connected to the Meissner corpuscles respond with a burst of action potentials to the onset and offset of mechanical stimulation (Vallbo and Johansson, 1984). Pacinian corpuscles are exquisitely sensitive to vibration and are electrophysiologically termed rapidly adapting type 2 (RA2) (Vallbo and Johansson, 1984).

A number of studies examined samples from the glabrous skin of human fingers obtained during autopsy or following amputation (Cauna, 1965; Bruce, 1980; Bruce and Sinclair, 1980; Iwasaki et al., 2003; Garcia-Piqueras et al., 2019). Details in age-related degeneration of cutaneous mechanoreceptors were studied using microscopy and immunohistochemistry in human skin from those in infancy to over 90 years old. After an early developmental propagation, Merkel cells decrease steadily in number with age (Cauna, 1965; Garcia-Piqueras et al., 2019), and there is a reduction of immunostaining for BDNF and TrkB, and a decrease in Piezo2 ion channels (Garcia-Piqueras et al., 2019). Pacinian corpuscles undergo dramatic morphological changes, growing up to six times in size over most of the life span, becoming 
more complex (Cauna, 1965), and they do not appear to reduce in number (Cauna, 1965; Garcia-Piqueras et al., 2019). A histological study on skin samples obtained from human glabrous skin during autopsy were analyzed for subjects in the age range 23-90 years (GarciaPiqueras et al., 2019). Interestingly, the structure of the Pacinian corpuscles, including the arrangement of corpuscular components and concentric lamellae, were similar across age groups. There were signs of loss of axonal innervation for a few Pacinian corpuscles from the older subjects, but overall the Pacinian corpuscles seem resistant to age-related degeneration.

Meissner corpuscles steadily decline in number with age (Cauna, 1965; Bruce, 1980; Bruce and Sinclair, 1980; Iwasaki et al., 2003). Compared to young people, Meissner corpuscles in older people show altered morphology (Cauna, 1965; Garcia-Piqueras et al., 2019), many lack axons (Garcia-Piqueras et al., 2019), and contrastingly, nerve endings sometimes remain after the loss of the corpuscle (Cauna, 1965). Meissner corpuscles also show less immunostaining for BDNF and TrkB with age, and there is a decrease in Piezo2 ion channels (Garcia-Piqueras et al., 2019). One important study has identified a potential role for Meissner corpuscles in agerelated declines in texture discrimination (Skedung et al., 2018). They reported that some older individuals have relatively well-preserved texture discrimination compared to others, and that these high performers also had a higher density of Meissner corpuscles in the finger pad, measured using a microscope. Curiously, another study found that age-related declines in touch detection thresholds for different skin regions do not reflect the age-related reductions in Meissner corpuscle density at a group level (Bruce, 1980; Bruce and Sinclair, 1980).

In the hairy skin, both thickly myelinated $A \beta$ and unmyelinated $C$ afferent fibres are associated with touch-sensitive primary afferents. Hairy skin lacks Meissner corpuscles but has Field mechanoreceptors whose axons have rapidly adapting properties (RA1) (Vallbo et al., 1995; Löken et al., 2009; Nagi et al., 2019). The hair follicle afferent (HFA) constitutes another 
type of RA mechanoreceptor that, as the name implies, is found exclusively in the hairy skin. Pacinian corpuscles are located more remotely in the hairy skin such as in the vicinity of joints and interosseous membrane (Calne and Pallis, 1966; Iggo and Ogawa, 1977). Hairy skin is also innervated by unmyelinated low-threshold mechanoreceptors (C-LTMRs) which are typically called C-tactile fibres (CTs) in the human literature (Nordin, 1990; Vallbo et al., 1993; Wiklund Fernstrom et al., 1999; Löken et al., 2009). The authors are not aware of any studies that have systematically examined the effects of ageing on C-tactile afferents.

\section{The central nervous system}

There are very few mechanistic studies on the effects of aging specifically on tactile processing. Hand representation in primary somatosensory cortex (S1) is expanded by about $40 \%$ in 60 to 85 -year-olds, compared to 19 to 35 -year-olds, and accompanies poorer spatial acuity in the same individuals (Kalisch et al., 2009). This is a puzzling finding that contrasts with the more typical association in younger adults between cortical map expansion and improved sensory performance, such as in string musicians (Elbert et al., 1995) and braille readers (Pascual-Leone and Torres, 1993), but may be a consequence of the reduction of intracortical inhibition developing with age.

More generally, the effects of aging on the human central nervous system include weight loss of the brain, which accelerates after age 70 and is attributed to the loss of myelin and neurons, with a total loss of up to $15 \%$ of the peak brain weight by age 90 . In addition, changes in cerebral blood flow and metabolism have been observed in the ageing brain (Yamaguchi et al., 1986; Goyal et al., 2017), which increases the risk of neurodegeneration. Although the specific functional consequences for touch sensation are unclear, there are cerebral vasculature and blood flow changes in the somatosensory cortex of aged mice (Li et al., 2018). Animal studies on the effects of ageing have also shown a brain-wide reduction in serotonin (Miguez 
et al., 1999), and in the parietal cortex, a reduction in serotonergic receptors and an increase in glutamate receptors (Wenk et al., 1989). Karrer et al. (2019) found a reduced serotonergic signal transmission in healthy aging with evidence of preservation of 5-HT-1A compared to 5-HT-2A receptors. The authors claim this reduction may partially explain psychological age differences such as why older adults use more emotion-focused rather than problem-focused coping strategies (Karrer et al., 2019).

In rodents, there is experimental evidence of reduced synaptic functioning with age in the somatosensory system, including the S1 and S2 cortices and thalamus (Voglewede et al., 2019). For whisker stimulation, aged mice show several differences in synaptic functioning compared to younger mice. The differences include reduced ability to remodel synaptic function (plasticity) and reduced integrity of the synapses. Such deficiency may be particularly detrimental when aged mice experience novel sensory stimuli, and the brain's capacity to incorporate them is affected. Furthermore, the degeneration of the CNS with age does not seem to be due to a loss of neurons but rather damage to the myelin of the neurons. The demyelination affects the conduction velocity of the CNS neurons, which in turn disrupts the timing of the nerve signals. Indeed, there is a correlation between demyelination and cognitive decline (Moss, 1999).

\section{Changes in touch perception}

Broadly, there are two aspects of touch sensation and perception. One aspect is the capacity to discriminate between different physical characteristics of a stimulus. For discriminative touch the rapidly conducting peripheral large myelinated afferents, the dorsal column, and the somatosensory cortices are of paramount importance (McGlone et al., 2014). Another aspect is the affective responses that can be evoked by tactile stimuli (Morrison et al., 2010). This could be feelings of calmness or joy when being touched by a loved one or 
feelings of disgust from an unwanted touch. The anatomical structures critical for affective touch are less known. In addition to large myelinated afferents, the slowly conducting unmyelinated peripheral afferents (C-tactile or CT) have an important role (Olausson et al., 2002; Löken et al., 2009). Stimuli of affective importance like stroking, squeezing or holding activate large-myelinated afferents and $\mathrm{C}$-tactile afferents in parallel. The information from these type of afferents is integrated at the dorsal horn (Abraira and Ginty, 2013), and transmitted to insular, orbitofrontal, superior temporal cortices, and beyond (Olausson et al., 2002; McGlone et al., 2012; Gordon et al., 2013; Davidovic et al., 2016). How affective touch is signalled in the spinal cord remains a mystery. In mice affective touch is projected in the anterolateral pathway (Choi et al., 2020) whereas in humans lesioning of the anterolateral tract does not alter affective touch perception (Marshall et al., 2019).

Discriminative aspects of tactile function are known to decline with age, including the ability to detect light touch (Newman, 1979; Bruce, 1980; Bruce and Sinclair, 1980; Thornbury and Mistretta, 1981), or vibration at different frequencies (Kenshalo, 1986; Thomson et al., 1993; Gescheider et al., 1994; Goble et al., 1996), to discriminate between different levels of surface roughness (Norman et al., 2016), or the distance between spatial features (Stevens, 1992; Stevens and Patterson, 1995; Stevens and Choo, 1996; Stevens et al., 1998; Desrosiers et al., 1999; Dinse et al., 2006), or to discriminate the direction of movement (Olausson et al., 1997; Lundblad et al., 2020). These capacities decline after around 60 years of age and this may be due to changing properties of the skin as well as neural degeneration of the peripheral and central nervous systems (Wickremaratchi and Llewelyn, 2006; Skedung et al., 2018). However, studies directly investigating these relationships have not yet established clear mechanisms for the functional decline (Bruce, 1980; Bruce and Sinclair, 1980; Escoffier et al., 1989; Cua et al., 1990; Schmidt and Wahren, 1990; Schmidt et al., 1990; Ishikawa et al., 1995; Skedung et al., 
2018). Given that this functional decline is well-established, the lack of a known mechanism is a clear gap in our knowledge.

Interestingly the pleasantness of being touched has been found to increase with age above 60 years in sharp contrast to the decrease in perceived intensity of touch, and the decline in discriminative tactile functions (Newman, 1979; Bruce, 1980; Bruce and Sinclair, 1980; Verrillo et al., 2002; Guest et al., 2014; Sehlstedt et al., 2016). In 120 healthy subjects of both sexes aged 13-82 years (Sehlstedt et al., 2016), the relationship between age and psychophysical ratings of intensity and pleasantness in response to gentle stroking touch was studied (Sehlstedt et al., 2016). The results show that touch intensity ratings are negatively correlated with age consistent with age-related decline of peripheral afferent function. Perhaps surprisingly there is a positive correlation between pleasantness ratings of touch and age. Furthermore, the number of emotional words used to describe gentle touch increases with age (Guest et al., 2014). However, May et al. (2014) found no effect of age on pleasantness ratings in a narrower age range (15-55 years).

The increase in touch pleasantness in later adulthood suggests that the peripheral unmyelinated (C) tactile afferents surmised to underpin touch pleasantness are somewhat resistant to age-related degeneration, akin to the Pacinian corpuscles. Since discriminative touch mediated by large myelinated afferents declines with age (cf. above), the relative contribution of C-tactile afferents to the tactile-evoked afferent barrage will be stronger. It is possible that a relatively stronger $\mathrm{C}$-tactile contribution may explain the higher pleasantness ratings with age. However another, perhaps more likely explanation is that the age-related increase in touch pleasantness is explained in psychological terms as a consequence of "longing for interpersonal touch" (Bessler et al., 2019) or "touch hunger" (Field, 2010). In other words, a reduction in the amount of interpersonal touch, which probably is more common in the 
elderly, may lead to increased enjoyment of touch (Sehlstedt et al., 2016). However, any explanation for the increase in touch pleasantness with aging remains speculative and mechanistic studies are required for further understanding of the phenomenon.

\section{Conclusion}

The age-related decline in tactile function is well-established, but precise neural mechanisms that link physiological and perceptual changes remain elusive. There exist multiple physical and neurophysiological changes throughout the lifespan that are candidates for explaining the functional decline. The skin loses elasticity and firmness with age. In the glabrous skin of the hands, a variety of receptor endings for mechanosensitive primary afferents undergo morphological changes and decline in number. Furthermore, demyelination in both the central and peripheral nervous system occur with ageing. Despite these many observed changes, attempts to find a strong link between their progression and the decline in functional performance on tactile tasks have failed. A satisfactory explanation of the mechanism needs to consider all these changes and how their effects combine. In addition, there is remarkably little data on the effects of ageing on hairy skin receptors, and on the social and emotional aspects of touch. 


\section{References}

Abraira VE, Ginty DD (2013), The sensory neurons of touch. Neuron 79:618-639.

Aimonetti JM, Deshayes C, Crest M, Cornuault PH, Weiland B, Ribot-Ciscar E (2019), Long Term Cosmetic Application Improves Tactile Discrimination in the Elderly; a New Psychophysical Approach. Front Aging Neurosci 11:164.

Akerman SC, Hossain S, Shobo A, Zhong Y, Jourdain R, Hancock MA, George K, Breton L, et al. (2019), Neurodegenerative Disease-Related Proteins within the Epidermal Layer of the Human Skin. J Alzheimers Dis 69:463-478.

Besne I, Descombes C, Breton L (2002), Effect of age and anatomical site on density of sensory innervation in human epidermis. Arch Dermatol 138:1445-1450.

Bessler R, Bendas J, Sailer U, Croy I (2019), The "Longing for Interpersonal Touch Picture Questionnaire": Development of a new measurement for touch perception. International Journal of Psychology 55:446-455.

Botchkarev VA, Kief S, Paus R, Moll I (1999), Overexpression of brain-derived neurotrophic factor increases Merkel cell number in murine skin. J Invest Dermatol 113:691-692.

Bouche P, Cattelin F, Saint-Jean O, Leger JM, Queslati S, Guez D, Moulonguet A, Brault Y, et al. (1993), Clinical and electrophysiological study of the peripheral nervous system in the elderly. J Neurol 240:263-268.

Bruce MF (1980), The relation of tactile thresholds to histology in the fingers of elderly people. J Neurol Neurosurg Psychiatry 43:730-734.

Bruce MF, Sinclair DC (1980), The relationship between tactile thresholds and histology in the human finger. J Neurol Neurosurg Psychiatry 43:235-242.

Cabo R, Alonso P, San Jose I, Vazquez G, Pastor JF, Germana A, Vega JA, Garcia-Suarez O (2015), Brain-derived neurotrofic factor and its receptor TrkB are present, but segregated, within mature cutaneous Pacinian corpuscles of Macaca fascicularis. Anat Rec (Hoboken) 298:624-629.

Calne DB, Pallis CA (1966), Vibratory sense: a critical review. Brain 89:723-746.

Cauna N (1965) The effects of aging on the receptor organs of the human dermis. In: Advances in Biology of Skin, vol. 6, pp. 63-96. New York: Pergamon Press.

Cavazzana A, Rohrborn A, Garthus-Niegel S, Larsson M, Hummel T, Croy I (2018), Sensoryspecific impairment among older people. An investigation using both sensory thresholds and subjective measures across the five senses. PLoS One 13:e0202969.

Chambers MR, Andres KH, von Duering M, Iggo A (1972), The structure and function of the slowly adapting type II mechanoreceptor in hairy skin. Q J Exp Physiol Cogn Med Sci 57:417-445.

Chang YC, Lin WM, Hsieh ST (2004), Effects of aging on human skin innervation. Neuroreport 15:149-153. 
Chesler AT, Szczot M, Bharucha-Goebel D, Ceko M, Donkervoort S, Laubacher C, Hayes LH, Alter K, et al. (2016), The Role of PIEZO2 in Human Mechanosensation. N Engl J Med 375:1355-1364.

Choi S, Hachisuka J, Brett MA, Magee AR, Omori Y, Iqbal NU, Zhang D, DeLisle MM, et al. (2020), Parallel ascending spinal pathways for affective touch and pain. Nature 587:258-263.

Corbin KB, Gardner ED (1937), Decrease in number of myelinated fibers in human spinal roots with age. The Anatomical Record 68:63-74.

Cua AB, Wilhelm KP, Maibach HI (1990), Elastic properties of human skin: relation to age, sex, and anatomical region. Arch Dermatol Res 282:283-288.

Davidovic M, Jonsson EH, Olausson H, Bjornsdotter M (2016), Posterior Superior Temporal Sulcus Responses Predict Perceived Pleasantness of Skin Stroking. Front Hum Neurosci $10: 432$.

Desrosiers J, Hebert R, Bravo G, Rochette A (1999), Age-related changes in upper extremity performance of elderly people: a longitudinal study. Exp Gerontol 34:393-405.

Dinse HR, Kleibel N, Kalisch T, Ragert P, Wilimzig C, Tegenthoff M (2006), Tactile coactivation resets age-related decline of human tactile discrimination. Ann Neurol 60:88-94.

Elbert T, Pantev C, Wienbruch C, Rockstroh B, Taub E (1995), Increased cortical representation of the fingers of the left hand in string players. Science 270:305-307.

Escoffier C, de Rigal J, Rochefort A, Vasselet R, Leveque JL, Agache PG (1989), Age-related mechanical properties of human skin: an in vivo study. J Invest Dermatol 93:353-357.

Field T (2010), Touch for socioemotional and physical well-being: A review. Developmental review 30:367-383.

Garcia-Piqueras J, Garcia-Mesa Y, Carcaba L, Feito J, Torres-Parejo I, Martin-Biedma B, Cobo J, Garcia-Suarez O, et al. (2019), Ageing of the somatosensory system at the periphery: age-related changes in cutaneous mechanoreceptors. J Anat 234:839-852.

Gescheider GA, Beiles EJ, Checkosky CM, Bolanowski SJ, Verrillo RT (1994), The effects of aging on information-processing channels in the sense of touch: II. Temporal summation in the P channel. Somatosens Mot Res 11:359-365.

Goble AK, Collins AA, Cholewiak RW (1996), Vibrotactile threshold in young and old observers: the effects of spatial summation and the presence of a rigid surround. $\mathrm{J}$ Acoust Soc Am 99:2256-2269.

Gordon I, Voos AC, Bennett RH, Bolling DZ, Pelphrey KA, Kaiser MD (2013), Brain mechanisms for processing affective touch. Human brain mapping 34:914-922.

Goyal MS, Vlassenko AG, Blazey TM, Su Y, Couture LE, Durbin TJ, Bateman RJ, Benzinger TL, et al. (2017), Loss of Brain Aerobic Glycolysis in Normal Human Aging. Cell Metab 26:353-360 e353. 
Guest S, Mehrabyan A, Ackerley R, McGlone F, Phillips N, Essick G (2014), Tactile experience does not ameliorate age-related reductions in sensory function. Exp Aging Res 40:81-106.

Hertenstein MJ, Holmes R, McCullough M, Keltner D (2009), The communication of emotion via touch. Emotion 9:566-573.

Iggo A, Muir AR (1969), The structure and function of a slowly adapting touch corpuscle in hairy skin. J Physiol 200:763-796.

Iggo A, Ogawa H (1977), Correlative physiological and morphological studies of rapidly adapting mechanoreceptors in cat's glabrous skin. J Physiol 266:275-296.

Ishikawa T, Ishikawa O, Miyachi Y (1995), Measurement of skin elastic properties with a new suction device (I): Relationship to age, sex and the degree of obesity in normal individuals. J Dermatol 22:713-717.

Iwasaki T, Goto N, Goto J, Ezure H, Moriyama H (2003), The aging of human Meissner's corpuscles as evidenced by parallel sectioning. Okajimas Folia Anat Jpn 79:185-189.

Kalisch T, Ragert P, Schwenkreis P, Dinse HR, Tegenthoff M (2009), Impaired tactile acuity in old age is accompanied by enlarged hand representations in somatosensory cortex. Cereb Cortex 19:1530-1538.

Karrer TM, McLaughlin CL, Guaglianone CP, Samanez-Larkin GR (2019), Reduced serotonin receptors and transporters in normal aging adults: a meta-analysis of PET and SPECT imaging studies. Neurobiol Aging 80:1-10.

Kenshalo DR, Sr. (1986), Somesthetic sensitivity in young and elderly humans. J Gerontol 41:732-742.

LeMaster AM, Krimm RF, Davis BM, Noel T, Forbes ME, Johnson JE, Albers KM (1999), Overexpression of brain-derived neurotrophic factor enhances sensory innervation and selectively increases neuron number. J Neurosci 19:5919-5931.

Li Y, Choi WJ, Wei W, Song S, Zhang Q, Liu J, Wang RK (2018), Aging-associated changes in cerebral vasculature and blood flow as determined by quantitative optical coherence tomography angiography. Neurobiol Aging 70:148-159.

Löken LS, Wessberg J, Morrison I, McGlone F, Olausson H (2009), Coding of pleasant touch by unmyelinated afferents in humans. Nature neuroscience 12:547-548.

Lumpkin EA, Caterina MJ (2007), Mechanisms of sensory transduction in the skin. Nature 445:858-865.

Lundblad LC, Olausson H, Wasling P, Jood K, Wysocka A, Hamilton JP, McIntyre S, Backlund Wasling H (2020), Tactile direction discrimination in humans after stroke. Brain Communications 2.

Marshall AG, Sharma ML, Marley K, Olausson H, McGlone FP (2019), Spinal signalling of $\mathrm{C}$-fiber mediated pleasant touch in humans. Elife 8. 
May AC, Stewart JL, Tapert SF, Paulus MP (2014), The effect of age on neural processing of pleasant soft touch stimuli. Frontiers in behavioral neuroscience 8:52.

McGlone F, Olausson H, Boyle JA, Jones-Gotman M, Dancer C, Guest S, Essick G (2012), Touching and feeling: differences in pleasant touch processing between glabrous and hairy skin in humans. The European journal of neuroscience 35:1782-1788.

McGlone F, Wessberg J, Olausson H (2014), Discriminative and affective touch: sensing and feeling. Neuron 82:737-755.

McIntyre S, Moungou A, Boehme R, Isager PM, Lau F, Israr A, Lumpkin EA, Abnousi F, et al., Affective touch communication in close adult relationships, 2019 IEEE World Haptics Conference (WHC), 2019, pp. 175-180.

Miguez JM, Aldegunde M, Paz-Valinas L, Recio J, Sanchez-Barcelo E (1999), Selective changes in the contents of noradrenaline, dopamine and serotonin in rat brain areas during aging. J Neural Transm (Vienna) 106:1089-1098.

Morrison I, Löken LS, Olausson H (2010), The skin as a social organ. Experimental brain research 204:305-314.

Moss MB, Killiany, R. J., Herndon, J. G. (1999) Age-Related Cognitive Decline in the Rhesus Monkey. In: Cerebral Cortex: Neurodegenerative and Age-Related Changes in Structure and Function of Cerebral Cortex vol. (A. Peters JHM, ed), pp. 21-47. Springer US.

Nagi SS, Marshall AG, Makdani A, Jarocka E, Liljencrantz J, Ridderstrom M, Shaikh S, O'Neill F, et al. (2019), An ultrafast system for signaling mechanical pain in human skin. Sci Adv 5:eaaw1297.

Newman HF (1979), Palatal sensitivity to touch: correlation with age. J Am Geriatr Soc $27: 319$.

Nordin M (1990), Low-threshold mechanoreceptive and nociceptive units with unmyelinated (C) fibres in the human supraorbital nerve. J Physiol 426:229-240.

Norman JF, Adkins OC, Hoyng SC, Dowell CJ, Pedersen LE, Gilliam AN (2016), Aging and the Haptic Perception of Material Properties. Perception 45:1387-1398.

Ochoa J, Mair WG (1969), The normal sural nerve in man. II. Changes in the axons and Schwann cells due to ageing. Acta Neuropathol 13:217-239.

Olausson H, Lamarre Y, Backlund H, Morin C, Wallin BG, Starck G, Ekholm S, Strigo I, et al. (2002), Unmyelinated tactile afferents signal touch and project to insular cortex. Nature neuroscience 5:900-904.

Olausson H, Norrsell U, Gothner K, Wallin BG (1997), Directional sensibility for quantification of tactile dysfunction. Muscle Nerve 20:1414-1421.

Palve SS, Palve SB (2018), Impact of Aging on Nerve Conduction Velocities and Late Responses in Healthy Individuals. J Neurosci Rural Pract 9:112-116. 
Pascual-Leone A, Torres F (1993), Plasticity of the sensorimotor cortex representation of the reading finger in Braille readers. Brain 116 ( Pt 1):39-52.

Ranade SS, Woo SH, Dubin AE, Moshourab RA, Wetzel C, Petrus M, Mathur J, Begay V, et al. (2014), Piezo2 is the major transducer of mechanical forces for touch sensation in mice. Nature 516:121-125.

Schmidt RF, Wahren LK (1990), Multiunit neural responses to strong finger pulp vibration. II. Comparison with tactile sensory thresholds. Acta Physiol Scand 140:11-16.

Schmidt RF, Wahren LK, Hagbarth KE (1990), Multiunit neural responses to strong finger pulp vibration. I. Relationship to age. Acta Physiol Scand 140:1-10.

Sehlstedt I, Ignell H, Backlund Wasling H, Ackerley R, Olausson H, Croy I (2016), Gentle touch perception across the lifespan. Psychol Aging 31:176-184.

Skedung L, El Rawadi C, Arvidsson M, Farcet C, Luengo GS, Breton L, Rutland MW (2018), Mechanisms of tactile sensory deterioration amongst the elderly. Sci Rep 8:5303.

Stevens JC (1992), Aging and spatial acuity of touch. J Gerontol 47:P35-40.

Stevens JC, Choo KK (1996), Spatial acuity of the body surface over the life span. Somatosens Mot Res 13:153-166.

Stevens JC, Cruz LA, Marks LE, Lakatos S (1998), A multimodal assessment of sensory thresholds in aging. J Gerontol B Psychol Sci Soc Sci 53:P263-272.

Stevens JC, Patterson MQ (1995), Dimensions of spatial acuity in the touch sense: changes over the life span. Somatosens Mot Res 12:29-47.

Thomson FJ, Masson EA, Boulton AJ (1993), The clinical diagnosis of sensory neuropathy in elderly people. Diabet Med 10:843-846.

Thornbury JM, Mistretta CM (1981), Tactile sensitivity as a function of age. J Gerontol 36:34-39.

Tohgi H, Tsukagoshi H, Toyokura Y (1977), Quantitative changes with age in normal sural nerves. Acta Neuropathol 38:213-220.

Vallbo AB, Johansson RS (1984), Properties of cutaneous mechanoreceptors in the human hand related to touch sensation. Hum Neurobiol 3:3-14.

Vallbo AB, Olausson H, Wessberg J, Kakuda N (1995), Receptive field characteristics of tactile units with myelinated afferents in hairy skin of human subjects. J Physiol 483 ( Pt 3):783-795.

Vallbo AB, Olausson H, Wessberg J, Norrsell U (1993), A system of unmyelinated afferents for innocuous mechanoreception in the human skin. Brain research 628:301-304.

Verdu E, Ceballos D, Vilches JJ, Navarro X (2000), Influence of aging on peripheral nerve function and regeneration. J Peripher Nerv Syst 5:191-208. 
Verrillo RT, Bolanowski SJ, Gescheider GA (2002), Effect of aging on the subjective magnitude of vibration. Somatosens Mot Res 19:238-244.

Voglewede RL, Vandemark KM, Davidson AM, DeWitt AR, Heffler MD, Trimmer EH, Mostany R (2019), Reduced sensory-evoked structural plasticity in the aging barrel cortex. Neurobiol Aging 81:222-233.

Wang L, Zhou H, Zhang M, Liu W, Deng T, Zhao Q, Li Y, Lei J, et al. (2019), Structure and mechanogating of the mammalian tactile channel PIEZO2. Nature 573:225-229.

Wellnitz SA, Lesniak DR, Gerling GJ, Lumpkin EA (2010), The regularity of sustained firing reveals two populations of slowly adapting touch receptors in mouse hairy skin. $\mathrm{J}$ Neurophysiol 103:3378-3388.

Wenk GL, Pierce DJ, Struble RG, Price DL, Cork LC (1989), Age-related changes in multiple neurotransmitter systems in the monkey brain. Neurobiol Aging 10:11-19.

Wickremaratchi MM, Llewelyn JG (2006), Effects of ageing on touch. Postgrad Med J 82:301-304.

Wiklund Fernstrom K, Wessberg J, Olausson H, Vallbo A (1999), Our second touch system: Receptive field properties of unmyelinated tactile afferents in man. Acta Physiol Scand 167:A26.

Woo SH, Ranade S, Weyer AD, Dubin AE, Baba Y, Qiu Z, Petrus M, Miyamoto T, et al. (2014), Piezo2 is required for Merkel-cell mechanotransduction. Nature 509:622-626.

Yamaguchi T, Kanno I, Uemura K, Shishido F, Inugami A, Ogawa T, Murakami M, Suzuki K (1986), Reduction in regional cerebral metabolic rate of oxygen during human aging. Stroke 17:1220-1228.

Zhang S, Duan E (2018), Fighting against Skin Aging: The Way from Bench to Bedside. Cell Transplant 27:729-738. 